\title{
EDITORIAL
}

IN this issue emphasis has been laid on the dangers of water sport with special reference to diving, with a lively discussion following the articles. It is quite clear that the preventive measures are not yet satisfactory especially with regard to the education of children, who start swimming from the age of 5. It cannot be emphasised too strongly that schoolchildren should be taught regarding the dangers of diving as much as they are taught to cross from one side of the street to the other. Moreover, local authorities should give this point much greater attention. In this respect it would be a great help for teachers if the local authorities could send directions in pamphlet form to the schools in their district.

As I suggested in the discussion, our Society should collect all the data with a view to making an official approach to Governments in various countries emphasising that diving and other water sport injuries produce as a rule fractures of the cervical spine resulting in tetraplegia, which transforms a young person between the ages of 15 and 25 from a healthy individual into a helpless wreck.

SiR LUDWIG GutTMANN

\section{STOP PRESS}

IT is with great regret that we report that Sir Ludwig Guttmann suffered a severe heart attack leading to his death on I8th March 1980. A full obituary will appear in the June 1980 issue. 